ty to develop and enhance research communication skills through a concise presentation. An undergraduate research session, two gradvate student sessions, and one research design session were held virtually, with one graduate student session held in person in Seattle. The symposium also coincided with other emerging scholar events on Saturday, including the Graduate School Information Fair and the Graduate Student Happy Hour in Seattle. The fourth annual TLCat-APSA-a "conference within a conference" for the scholarship of teaching and learning was also held throughout the day.

APSA also hosted an in-person exhibit hall, as well as virtual hall. The virtual hall is still available for engagement with exhibitors on the virtual plafform. Additionally, many presenters participated in our iPosters presentations, and the gallery is still available for viewing and feedback post-conference: https://connect.apsanet.org/ apsa2021/iposter-sessions/.

Additional scholars opted for the flexibility of pre-recording their presentations. These presentations are available on the virtual platform and can be viewed. There is an option to provide feedback on these, as well. Conference registrants, both in-person and virtual attendees, will be able to access all recorded content on the virtual meeting plafform until March: https://apsa2021.conventus.live/ login. Select meeting sessions are on demand to all APSA members
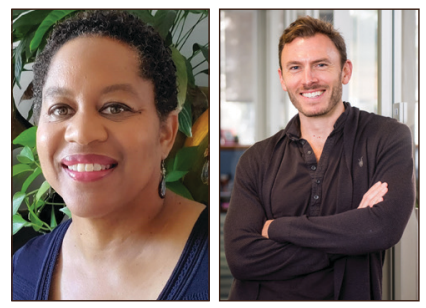
and can be found here: https:// apsanet.org/EVENTS/Annual-Meeting-Exhibition/2021-Annual-Meeting-Video-Highlights.

Reflecting on the year's theme, program co-chair Dino Christenson was "delighted to see

Above: Program co-chair Valeria Sinclair-Chapman (left) and co-chair Dino Christenson (right). scholars embrace and promote the rich intellectual pluralism of our discipline at the Annual Meeting." He furthered: "Our heterogeneity should be a hallmark of political science and an opportunity to lead other social sciences. This year's meeting showcased the resilience and multidimensional diversity our discipline has to offer, with panels and papers that push us away from silos and toward respect, engagement, and celebration of a wide array of scholars, methods, methodologies and approaches." Program co-chair Valeria Sinclair-Chapman hopes that "APSA members will take the call to pluralism in the discipline seriously by heeding the call to invest in the diversity of scholars and scholarship in the discipline. Doing so will pay dividends through identifying new questions, building on intersectionalities, broadening career pathways in the discipline, and finding novel ways to solve problems." Thank you again to all who contributed to a successful 2021 event-both in-person and virtually!

Looking forward, the 2022 Annual Meeting will be held in Montréal, Québec, Canada, from September 15-18. Currently, the call for proposals is open until January 18, 2022. The theme is "Rethink, Restructure, and Reconnect: Towards a Post-Pandemic Political Science" and can be viewed on the 2022 Annual Meeting website. APSA President John Ishiyama, University of North Texas, and the 2022 Program co-chairs, Sherri Wallace, University of Louisville, and Pei-Te Lien, University of California - Santa Barbara, look forward to your participation in panels and sessions prepared by APSA's 60 divisions and numerous related groups at the 2022 APSA Annual Meeting and Exhibition.

\title{
Congresswoman Robin Kelly Addresses APSA Annual Meeting
}

\section{ABBY PAULSON | ASSOCIATE DIRECTOR, GOVERNMENT RELATIONS AND PUBLIC ENGAGEMENT}

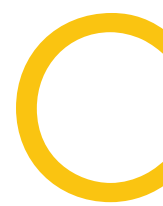

ongresswoman Robin Kelly has represented the 2nd district of Illinois since 2013, and brings a vital perspective to Congress having also earned a PhD in Political Science from Northern Illinois University. Only three other political scientists currently serve in Congress, Representatives David Price, Dina Titus, and Henry Cuellar. Freshman Congresswoman Carolyn Bourdeaux holds a PhD in Public Administration, and Rep. Mike Gallagher has a PhD in International Relations.

Kelly addressed the 2021 APSA Annual Meeting via pre-recorded remarks, reflecting on her experience in Congress. Her remarks highlighted the challenges of a polarized legislative body.

"Since coming to Congress following a special election in 2013, the past 18 months have represented some of the most challenging days of this job," Kelly said. "As a nation, we have endured a global pandemic, which is showing no signs of stopping, the economic impacts of that pandemic, increased gun violence, and a national reckoning on police violence and systemic racism. The stakes of our decision making are very high, and compromise in the halls of Congress can be hard to come by."
Kelly also makes clear that the events of January 6 changed how some members interact. "I was one of the Members stranded in the House gallery, on my hands and knees on the floor, hiding behind chairs as we listened to the insurrectionists screaming in the hallway and heard gunshots in the halls of the Capitol," said Kelly. "Knowing that some Members incited this violence and gravely serious attack on our Capitol building and democracy has changed my perspective about working across the aisle. There are some Members who I will no longer consider working with because of their role in the January 6th attack. I know many of my Democratic colleagues feel the same way."

The Congresswoman's remarks also touch on her efforts to be responsive to her diverse constituency, and her leadership in caucuses and the Democratic party. The remarks will remain available for viewing on the APSA Annual Meeting platform. 